See Article page 27.

\section{Commentary: Mitral valve neo-chords, still a lot to learn!}

\author{
Francisco Diniz Affonso da Costa, MD
}

Mitral valve repair is the standard-of-care treatment for patients with leaflet prolapse and severe valvular regurgitation secondary to fibroelastic deficiency or myxomatous degenerative disease. To obtain a successful and durable result, multiple resectional and nonresectional surgical maneuvers must be individually applied at cusp, chordae, papillary muscle, and annular levels to address a wide variety of anatomical lesions responsible for valve dysfunction.

In combination with other maneuvers, the use of expanded polytetrafluoroethylene sutures to correct leaflet prolapse and reinforce regions supported by thin and fragile native chordae tendineae has proved to be an effective and durable technique to obtain a competent valve. ${ }^{2}$ However, adjusting for proper neochordae length may be not so simple as originally thought, and several different methods for accomplishing the ideal length have been proposed.

The tedious and elegant computational model of Caballero and colleagues ${ }^{3}$ published in this issue of the JTCVS Open sheds light and demonstrates in a rigorous scientific way that minor variations during neochordae implantation such as length, position, angulation, and number of implanted chords can induce significant augmented neochordae tension and leaflet stress that may be responsible for late failures despite an apparent favorable initial result. Although their original intention was to provide an improved understanding of biomechanical forces after transapical off-pump neochordae implantation, the data and concepts also have important implications during open repairs, be it through sternotomy, minimally invasive, or robotic approaches.

\footnotetext{
From Cardiovascular Surgery INC-Cardio and Santa Casa de Curitiba, Pontificia Universidade Católica do Paraná (PUCPR), Curitiba, Paraná, Brazil.

Disclosures: The author reported no conflicts of interest.

The Journal policy requires editors and reviewers to disclose conflicts of interest and to decline handling or reviewing manuscripts for which they may have a conflict of interest. The editors and reviewers of this article have no conflicts of interest.

Received for publication June 14, 2020; revisions received June 14, 2020; accepted

for publication June 19, 2020; available ahead of print July 29, 2020.

Address for reprints: Francisco Diniz Affonso da Costa, MD, Rua Henrique Coelho

Neto, 55, 82200-120 Curitiba, Paraná, Brazil (E-mail: fcosta13@mac.com).

JTCVS Open 2020;3:45

2666-2736

Copyright (C) 2020 The Authors. Published by Elsevier Inc. on behalf of The American Association for Thoracic Surgery. This is an open access article under the CC BY-NCND license (http://creativecommons.org/licenses/by-nc-nd/4.0/).

https://doi.org/10.1016/j.xjon.2020.06.009
}

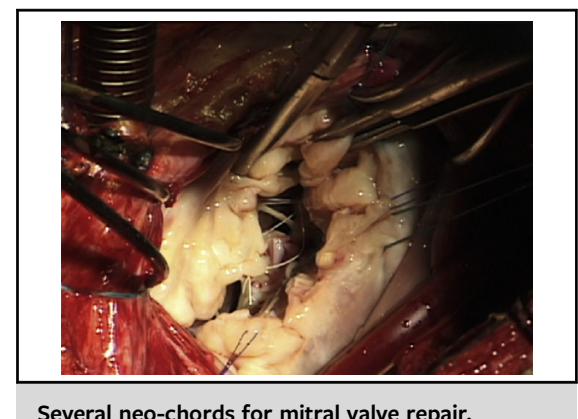

Several neo-chords for mitral valve repair.

\section{CENTRAL MESSAGE \\ Off-pump transapical mitral neo- \\ chord implantation is still in a \\ developing stage. Basic experi- \\ mental research is fundamental \\ to improve clinical results.}

Mitral valve repair, when performed by experienced surgeons, can be performed with very low operative mortality, low recurrence rates, and excellent long-term survival. ${ }^{2}$ However, most series do not include a significant proportion of elderly and fragile patients with multiple comorbidities. Patients with this profile are frequently denied surgery and often left in medical treatment alone. Although currently it is difficult to justify an off-pump transapical approach for low- and intermediate-risk patients, a less-invasive procedure may be a reasonable option in selected high-risk or inoperable patients. Although initial experience with alternative procedures such as MitraClip and off-pump neochordae implantation has been associated with greater incidences of persistent and recurrent mitral regurgitation, they may well represent an adequate palliation in otherwiseinoperable patients. ${ }^{4}$ Meanwhile, basic research work such as that presented by Caballero and colleagues will be fundamental to improve new technologies that should be carefully evaluated in proper designed clinical trials before being applied in a more generalized way.

\section{References}

1. El-Eshmawi A, Castillo JG, Tang GHL, Adams DH. Developing a mitral valve center of excellence. Curr Opin Cardiol. 2018;33:155-61.

2. David TE, David CM, Tsang W, Lafreniere-Roula M, Manlhiot C. Long-term results of mitral valve repair for regurgitation due to leaflet prolapse. J Am Coll Cardiol. 2019;74:1044-53.

3. Caballero A, McKay R, Sun W. Computer simulations of transapical mitral valve repair with neochordae implantation: clinical implications. J Thorac Cardiovas Surg Open. 2020;3:27-44.

4. Colli A, Manzan E, Aidietis A, Rucinskas K, Bizzotto E, Besola L, et al. An early European experience with transapical off-pump mitral valve repair with NeoChord implantation. Eur J Cardiothorac Surg. 2018;54:460-6. 